Research Article

\title{
Genetic structure of red-handed howler monkey populations in the fragmented landscape of Eastern Brazilian Amazonia
}

\author{
Heitor B. Bastos ${ }^{1}$, Evonnildo C. Gonçalves ${ }^{1}$, Stephen F. Ferrari ${ }^{2}$, Artur Silva ${ }^{1}$ and Maria Paula C. Schneider ${ }^{1}$ \\ ${ }^{1}$ Laboratório de Polimorfismo do DNA, Departamento de Genética, Universidade Federal do Pará, Belém, \\ PA, Brazil. \\ ${ }^{2}$ Departamento de Biologia, Universidade Federal de Sergipe, São Cristóvão, SE, Brazil.
}

\begin{abstract}
We genotyped 15 microsatellite loci in order to evaluate the effects of habitat fragmentation, caused by flooding of the Tucuruí reservoir, on the genetic structure of Alouatta belzebul in eastern Amazonia. The analysis included two populations sampled in 1984, representing both margins of the Tocantins river, and three populations sampled 18 years later. Minimal differences in the diversity levels between present-day $\left(H o=0.62-0.69\right.$ and $\left.A_{R}=6.07-7.21\right)$ and pre-flooding ( $\mathrm{Ho}=0.60-0.62$ and $\left.A_{R}=6.27-6.77\right)$ populations indicated there was no significant loss of genetic variability, possibly because of successful management strategies applied during the flooding. The changes observed were limited to shifts in the composition of alleles, which presumably reflect the admixture of subpopulations during flooding. Given this, there were significant differences in the Rst values $(p=0.05)$ in all but one between-site comparison. Both present-day and original populations showed a deficit of heterozygotes, which suggests that this may be typical of the species, at least at a local level, perhaps because of specific ecological characteristics. The relatively large number of private alleles recorded in all populations may be a consequence of the Wahlund effect resulting from population admixture or a process of expansion rather than the loss of rare alleles through genetic drift. Additionally, the levels of genetic variability observed in this study were higher than those reported for other species of Neotropical primates, suggesting good fitness levels in these A. belzebul populations. Regular genetic monitoring of remnant populations, especially on islands, should nevertheless be an integral component of long-term management strategies.
\end{abstract}

Key words: Alouatta belzebul, Amazonia, conservation, genetic structure, habitat fragmentation.

Received: October 28, 2009; Accepted: July 13, 2010.

\section{Introduction}

Endemic to Brazil, the red-handed howler (Alouatta belzebul) is found in the southeastern Amazon basin and northern Atlantic Forest (Gregorin, 2006). Like other members of the genus (Di Fiore and Campbell, 2007), the red-handed howler is relatively tolerant of anthropogenic habitat disturbance (Bonvicino, 1989; Pinto et al., 2003; Camargo CC, MSc Dissertation, Museu Paraense Emílo Goeldi, Belém, PA, 2005), although Atlantic Forest populations have been reduced to critical levels by deforestation. In contrast, Amazonian populations are relatively abundant, despite the comparatively high deforestation rates that affect the densely-populated southeastern basin (Lopes and Ferrari, 2000).

Among other major impacts in this region, the construction in the early 1980s of the world's fourth-largest hydroelectric dam (based on generating capacity) at Tucuruí

Send correspondence to Evonnildo Costa Gonçalves. Laboratório de Polimorfismo do DNA, Caixa Postal 8607, 66075-970, Belém, PA, Brazil.E-mail: ecostag@ufpa.br. on the Tocantins river resulted in the creation of a $2500 \mathrm{~km}^{2}$ reservoir and the formation of more than 1600 islands. In addition to increasing the distance between opposite banks of the river from approximately $1 \mathrm{~km}$ to up to $30 \mathrm{~km}$ in places, construction of the dam initiated a process of intense human colonization in the area around the reservoir, which resulted in the fragmentation of most of the surrounding forest (Figure 1). Howlers were among the most abundant mammals prior to the flooding (Mascarenhas and Puorto, 1988), and currently have high population densities, especially on islands (Camargo and Ferrari, 2007), although the area's total population is almost certainly much smaller than it was prior to the flooding. Similarly, while there are no data on migration patterns, either before or after the flooding, it seems likely that dispersal is now restricted to the islands closest to each margin of the Tocantins and that cross-river transfer is practically nil.

Samples collected from some of the animals rescued during the flooding are still available, and the primary aims of the present study were to investigate the genetic structure of the original populations they represent, using molecular 


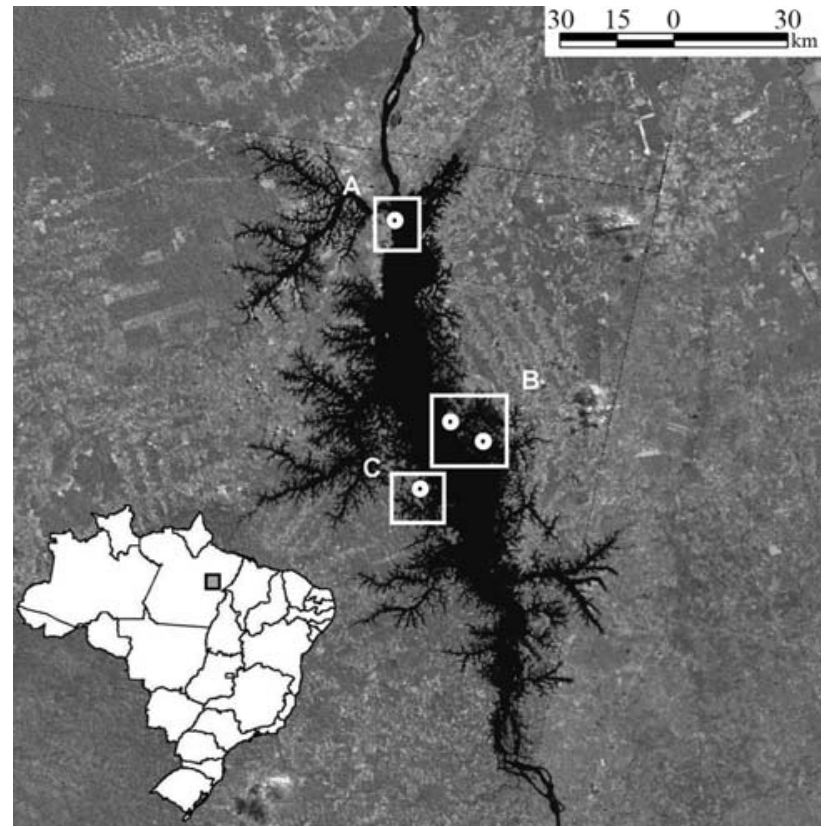

Figure 1 - Map of the study area based on satellite imagery, showing the Tucuruí reservoir (center) and the sampling localities mentioned in the text. The Tocantins river (in black) runs south-north. In the surrounding matrix, darker gray areas are forest, while lighter coloration indicates pasture or plantations. A includes LB02 = Germoplasma Island in 2002, representing the left bank of the Tocantins post-flooding, B includes RB85 = Base 4 in 1985, representing the right bank prior to flooding, RB02 $=$ Base 4 in 2002, representing the right bank post-flooding, and $\mathrm{RB} 02 \mathrm{~B}=$ Cornélio Island in 2002, an isolated post-flooding right bank population, C includes LB85 = Base 3 in 1985, representing the left bank prior to flooding of the reservoir.

techniques not available in the 1980 s, and to assess the long-term effects of the flooding on the structure of present-day populations. The isolation of relatively small populations on islands may lead to increased inbreeding and random effects such as genetic drift (Couvet, 2002; Frankham, 2003). These processes may cause a loss of genetic variability, and possible fixation of deleterious alleles, which in turn can lead to the loss of long-term population viability (Bjilsma et al., 2000; Frankham et al., 2002; Keller and Waller, 2002; Reed and Frankham, 2003).

\section{Material and Methods}

\section{Samples and DNA extraction}

The samples analyzed in this study represent five spatially and temporally distinct populations of eastern Amazonian red-handed howlers (Alouatta belzebul) from the area of the Tucuruí hydroelectric reservoir $\left(4^{\circ} 15^{\prime} \mathrm{S}\right.$, $49^{\circ} 31^{\prime} \mathrm{W}$ ) in the Brazilian state of Pará (Figure 1). Blood samples (3-6 mL) were collected via venal puncture from 989 of the howlers captured during flooding of the reservoir, in 1984 and 1985. Aliquots of these samples were stored at the Universidade Federal do Pará in Belém. Most of these samples were used in the study of Schneider et al. (1991), but for the present study, it was only possible to ex- tract DNA from 40 of the specimens. Of these, 30 were collected on the left bank (LB85) of the Tocantins and 10 on the right bank (RB85).

In 2002, howlers were captured live at three sites in the Tucuruí reservoir using a Pneu-dart rifle and tranquilizer darts containing $0.1 \mathrm{~mL}$ of ketamine hydrochloride per $\mathrm{kg}$ body weight. Captures were authorized by the federal environment agency (IBAMA) and were supervised by a veterinarian from the National Primate Center in Belém. All procedures were conducted in compliance with federal animal care legislation. Blood samples of $\sim 3 \mathrm{~mL}$ were collected from the femoral vein of anesthetized howlers and stored in Falcon tubes containing $300 \mu \mathrm{L}$ of $0.02 \mathrm{M}$ EDTA. Thirty blood specimens were collected from howlers on the 129-ha Germoplasma Island (LB02), close to the present-day left bank of the Tocantins, and from 22 individuals on the right bank: 15 from Base 4 (RB02) and seven from Cornélio Island (RB02B; Figure 1), which is similar in size to Germoplasma Island. DNA was obtained from all samples using a standard protocol (Sambrook et al., 1989).

\section{Analysis of microsatellite loci}

Fifteen microsatellite loci were analyzed (Table 1). Ten of these were developed specifically for A. belzebul (Gonçalves et al., 2004), whereas the remaining five were specific for Callithrix jacchus (Nievergelt et al., 1998), Alouatta palliata (Ellsworth and Hoelzer, 1998) and Cebus apella (Escobar-Páramo, 2000). Polymerase chain reactions (PCRs) were done in a final volume of $20 \mu \mathrm{L}$, containing 0.5 unit of Taq DNA polymerase, $5 \mathrm{ng}$ of DNA, $25 \mu \mathrm{M}$ of each dNTP, $50 \mathrm{mM} \mathrm{KCl}, 10 \mathrm{mM}$ Tris- $\mathrm{HCl}$ and $0.4 \mu \mathrm{M}$ of each primer. Optimal conditions for the 15 primers were determined by varying the temperature of association (Table 1), number of cycles and the concentration of $\mathrm{MgCl}_{2}$.

Table 1 - The 15 microsatellite loci analyzed in this study.

\begin{tabular}{lccc}
\hline Locus & Temp $\left({ }^{\circ} \mathrm{C}\right)$ & Original species & Allele length (bp) \\
\hline Ab04 & 62 & Alouatta belzebul & $147-167$ \\
Ab06 & 50 & Alouatta belzebul & $265-293$ \\
Ab07 & 60 & Alouatta belzebul & $178-202$ \\
Ab09 & 53 & Alouatta belzebul & $168-204$ \\
Ab10 & 56 & Alouatta belzebul & $228-284$ \\
Ab12 & 60 & Alouatta belzebul & $223-293$ \\
Ab13 & 52 & Alouatta belzebul & $197-261$ \\
Ab16 & 58 & Alouatta belzebul & $198-244$ \\
Ab17 & 63 & Alouatta belzebul & $193-263$ \\
Ab20 & 67 & Alouatta belzebul & $242-304$ \\
Cj12 & 50 & Callithrix jacchus & $120-134$ \\
Cj14 & 50 & Callithrix jacchus & $138-148$ \\
Ap68 & 49 & Alouatta palliata & $180-206$ \\
Ap74 & 52 & Alouatta palliata & $128-158$ \\
Pepc8 & 60 & Cebus apella & $224-246$ \\
\hline
\end{tabular}


The standard PCR profile was: an initial cycle of 5 min at $94{ }^{\circ} \mathrm{C}$ for denaturation, followed by $20-30$ cycles of $1 \mathrm{~min}$ at $94{ }^{\circ} \mathrm{C}$ for denaturation, $1 \mathrm{~min}$ at $50-60^{\circ} \mathrm{C}$ for primer association and $1 \mathrm{~min}$ at $72{ }^{\circ} \mathrm{C}$ for extension, with a final incubation of $5 \mathrm{~min}$ at $72^{\circ} \mathrm{C}$ to guarantee complete extension of the PCR products. The PCR products were separated by size in $8 \%$ polyacrylamide gels in an ALF Express II automatic DNA sequencer (Amersham Bioscience). The size of the amplified fragments was determined using Allelinks 1.0 software.

\section{Detection of bottleneck events}

Recent bottleneck events often present genetic characteristics that can be detected in microsatellite data. Typically, allelic diversity is lost more quickly than heterozygosity, and observed heterozygosity is different from that expected based on the number of alleles under mutationdrift equilibrium (Cornuet and Luikart, 1996; Luikart and Cornuet, 1998). Allele frequencies were tested for the presence of an excess of heterozygotes using the sign test (Cornuet and Luikart, 1996) and Wilcoxon's signed-rank test, run on the Bottleneck program described by Piry et al. (1999). As the mechanisms of mutation in microsatellite markers are unknown, these tests were based on three different mutational models: the stepwise mutation model (SMM) (Kimura and Ohta, 1978), the infinite allele model (IAM) (Kimura and Crow, 1964), and the two-phase model (TPM) (Di Rienzo et al., 1994). The TPM was used in conjunction with 95\% SMM and 5\% IAM, which, according to Piry et al. (1999), is appropriate for microsatellite markers.

\section{Statistical analysis}

To characterize the genetic diversity of each population, allele frequencies, the mean number of alleles (A), observed $(\mathrm{Ho})$ and expected $(\mathrm{He})$ heterozygosities according to Hardy-Weinberg equilibrium, and their means, were calculated using Popgene32 (Yeh et al., 1997). Allelic richness $\left(A_{R}\right)$, an index of the number of alleles independent of sample size, was estimated using the Goudet (1995) FSTAT application via the rarefaction method adapted for genetic data by Petit et al. (1998). Possible deviations from Hardy-Weinberg equilibrium and an excess or deficiency of heterozygotes in a given population were evaluated using the exact probability test run on Genepop 3.1 (Raymond and Rousset, 1995). Genetic differentiation between populations was evaluated based on estimates of Rst, which is analogous to Fst (Wright, 1931). Arlequin 3.1 (Schneider et $a l ., 2000$ ) was used to calculate Rst and run an analysis of molecular variance (AMOVA) (Excoffier et al., 1992), which estimates the proportion of overall variance attributed to differences within and among artificial groups of the populations, and among individuals within each population. This analysis was done on all possible combinations of the five populations studied, although only the results (after Bonferroni correction; Rice, 1989) of the four most informative arrangements are presented here.

\section{Results}

\section{Genetic variability and bottlenecks}

Some of the loci, such as $\mathrm{Cj} 12$ and $\mathrm{Cj} 14$, were relatively homogeneous in terms of allele length, whereas others, in particular Ab12 and Ab20, were more variable (Table 1). The mean number of alleles per locus was relatively large in all populations, ranging from 6.1 at RB02B to 12.0 at LB02; estimates of allelic richness varied less, from 6.07 at RB02B to 7.21 at LB02 (Table 2).

Observed heterozygosity was relatively high $(\geq 0.60)$ in all populations (Table 2), although these values were consistently lower than expected $(\mathrm{He} \geq 0.78)$ for each population. All differences between the observed and expected heterozygosities were significant, even after applying the Bonferroni correction (Rice, 1989). This indicates that none of the populations was in Hardy-Weinberg equilibrium.

The results of the Bottleneck analyses (Table 3) varied considerably, depending on the mutational model used and the type of statistical test. In the case of the IAM, the analyses indicated that some populations (LB85, LB02 and RB02B) had or have suffered recent bottleneck events. However, this model is more appropriate for protein studies, and when the SMM and TPM were applied, this trend disappeared. In the case of SMM, the sign test yielded a significant result for LB85, although this was contradicted em-

Table 2 - Summary of the characteristics of 15 microsatellite loci in the A. belzebul populations studied at Tucuruí, and analysis of the deviation from Hardy-Weinberg equilibrium.

\begin{tabular}{|c|c|c|c|c|c|c|}
\hline Population (N) & $\mathrm{A}(\mathrm{SD})$ & $\mathrm{A}_{\mathrm{R}}$ & $\mathrm{P}_{\mathrm{A}}$ & Ho (SD) & $\mathrm{He}(\mathrm{SD})$ & $\mathrm{p}$ \\
\hline LB85 (30) & $11.27(4.93)$ & 6.77 & 20 & $0.60(0.27)$ & $0.83(0.09)$ & $<0.01$ \\
\hline RB85 (10) & $6.93(2.46)$ & 6.27 & 3 & $0.67(0.32)$ & $0.79(0.16)$ & $<0.01$ \\
\hline LB02 (30) & $12.00(4.26)$ & 7.21 & 37 & $0.69(0.20)$ & $0.86(0.07)$ & $<0.01$ \\
\hline RB02 (15) & $8.40(4.01)$ & 6.26 & 9 & $0.62(0.28)$ & $0.78(0.23)$ & $<0.01$ \\
\hline RB02B (07) & $6.07(2.25)$ & 6.07 & 5 & $0.67(0.25)$ & $0.78(0.21)$ & $<0.05$ \\
\hline
\end{tabular}

See Figure 1 and text for definition of populations. $A=$ mean number of alleles per locus, $A_{R}=$ allelic richness, $\mathrm{He}=$ expected heterozygosity, $\mathrm{Ho}=\mathrm{ob}-$ served heterozygosity, $\mathrm{N}=$ sample size, $\mathrm{p}=$ probability of deviation from Hardy-Weinberg equilibrium, $\mathrm{P}_{\mathrm{A}}=$ private alleles, $\mathrm{SD}=$ standard deviation. 
Table 3 - Values of p recorded for the statistical analyses (sign and Wilcoxon tests) of the different mutational models used to evaluate the probability of recent bottleneck events in the study populations, calculated using the Bottleneck program of Piry et al. (1999).

\begin{tabular}{|c|c|c|c|c|c|c|}
\hline \multirow[b]{3}{*}{ Population } & \multicolumn{6}{|c|}{ Value of $\mathrm{p}$ according to } \\
\hline & \multicolumn{2}{|c|}{ Infinite alleles model } & \multicolumn{2}{|c|}{ Stepwise mutation model } & \multicolumn{2}{|c|}{ Two-phase model } \\
\hline & Sign test & Wilcoxon test & Sign test & Wilcoxon test & Sign test & Wilcoxon test \\
\hline LB85 & 0.00043 & 0.00002 & 0.01191 & 0.95837 & 0.42747 & 0.68066 \\
\hline RB85 & 0.38652 & 0.15140 & 0.10613 & 0.87381 & 0.09296 & 0.83487 \\
\hline RB02 & 0.00858 & 0.00009 & 0.44556 & 0.40387 & 0.27522 & 0.33490 \\
\hline $\mathrm{RB} 02 \mathrm{~B}$ & 0.12625 & 0.07571 & 0.59758 & 0.33939 & 0.22683 & 0.24435 \\
\hline
\end{tabular}

See Figure 1 and text for definition of populations.

phatically by the Wilcoxon value (Table 3 ). Overall, these analyses indicated that none of the populations was experiencing or had experienced a recent bottleneck event.

\section{Genetic differentiation}

Values of pairwise Rst varied from -0.0109 (RB85 vs. RB02) to 0.2277 (LB85 vs. RB02B) (Table 4). With the exception of the comparison RB85 vs. RB02 (the same site in different years), all comparisons were significant $(\mathrm{p}<0.05)$, and those involving RB02B generally returned the highest values, as expected from the relative configuration of the sites, i.e., LB02 was more similar to LB85 than RB85, and so on. Despite being the most differentiated population, the Rst values for RB02B were consistent with its location in time and space, with smaller values for the $\mathrm{RB}$ populations and the smallest for the more recent RB02.

Other patterns were more complex, however, in particular the relatively low values recorded for RB02. Indeed, the negative value obtained for RB85 vs. RB02 suggested that there was more differentiation within each population than between them. RB02 was nevertheless more similar to both LB populations than it was to RB02B. This almost certainly reflects the admixture resulting from the release of rescued animals at Base 4, in contrast to Cornélio Island, which has remained isolated since the flooding.

\section{Analysis of molecular variance (AMOVA)}

Within-population variation accounted for $>90 \%$ of the molecular variance in all combinations of populations, except where RB02B was compared with the remaining populations (Table 5). In all other cases, the absence of variation between banks and the reduced variation among populations of the same bank was due to the inclusion of $\mathrm{RB} 02 \mathrm{~B}$ in the analysis.

\section{Discussion}

\section{Genetic variability}

A relatively large number of alleles was recorded per locus compared with other platyrrhines, e.g. Leontopithecus rosalia (Grativol et al., 2001) and Mico argentatus (Gonçalves et al., 2009). Despite these values, there was

Table 4 - Matrix of Rst values for pairwise comparisons between A. belzebul populations from Tucuruí.

\begin{tabular}{lccc}
\hline Population & LB85 & RB85 & LB02 \\
\hline RB85 & $0.0484 *$ & & \\
LB02 & $0.0592 * *$ & $0.1001 * *$ & $0.0504 * *$ \\
RB02 & $0.0370 *$ & -0.0109 & $0.1994^{* *}$ \\
RB02B & $0.2277^{* *}$ & $0.1170^{*}$ & $0.1090^{*}$ \\
\hline
\end{tabular}

See Figure 1 and text for definition of populations. ${ }^{*} \mathrm{p}<0.05 ; *{ }^{*} \mathrm{p}<0.01$.

Table 5 - AMOVA results for the principal arrangements of the A. belzebul populations from Tucuruí.

\begin{tabular}{lcc}
\hline Arrangement & Between groups & Among populations within each group \\
\hline LB85 - RB85 vs. RB02B - LB02 - RB02 & $-1.13 \%$ & $8.90 \%$ \\
LB02 vs. LB85 - RB85 - RB02B - RB02 & $-0.68 \%$ & $8.54 \%$ \\
RB02 vs. LB85 - RB85 - LB02 - RB02B & $-5.52 \%$ & $92.23 \%$ \\
RB02B vs. LB85 - RB85 - LB02 - RB02 & $14.76 \%$ & $9.43 \%$ \\
\hline
\end{tabular}

See Figure 1 and text for definition of populations. 
considerable variation among populations, which may be accounted for primarily by differences in sample size. Indeed, Leberg (2002) has suggested that estimates of allele numbers in genetically variable populations are relatively more vulnerable to differences in sample size than those for more homogeneous populations. In addition, Schlötterer et al. (2004) have shown that mean allele excess may be strongly influenced by sample size and $\theta$-values, and this seems to be the case with our data (not shown).

Unfortunately, the allelic richness parameter has not been used widely in studies of platyrrhines, which reduces its value for interspecific comparisons, although it does permit more conclusive inferences on differences among the populations studied here, without the bias of sample size. A comparison of allelic richness values (Table 2) indicated that overall the populations were relatively similar.

The heterozygosity values recorded here reconfirmed the relatively high genetic variability of the $A$. belzebul populations from Tucuruí, both before and after flooding of the reservoir. Once again, these values are also relatively high when compared with those for other microsatellite studies in platyrrhines: 0.49 (range: $0.34-0.65$ ) in L. rosalia (Grativol et al., 2001), $0.26(0.11-0.39)$ in $M$. argentatus (Gonçalves et al., 2009), 0.33 (0.09-0.65) in C. moloch (Menescal et al., 2009) and 0.47 (0-0.86) in Alouatta palliata (Milton et al., 2009).

The observed heterozygosity was significantly lower than expected in all five populations. However, this may be related to sampling questions, such as the Wahlund effect. In this case, the situation in the original populations (LB85 and RB85) might be explained by the admixture of different local subpopulations during flooding, although it seems likely that these populations, especially those on islands, have been relatively stable since then. However, the 18 years that separate the two periods represent only two or three howler generations (Di Fiore and Campbell, 2007), which may not yet have been sufficient for the populations to achieve equilibrium.

\section{Differences among populations}

The Rst values (Table 4) indicated relatively limited differentiation among populations, except for comparisons involving Cornélio Island. By comparison, Grativol et al. (2001) obtained values between 0.25 and 0.45 for pairwise comparisons of four isolated populations of $L$. rosalia in a fragmented habitat. In particular, the similarity between the left and right bank populations of $A$. belzebul suggests that the original course of the Tocantins river was not a very effective barrier to dispersal between the region's original populations. This might be expected, given the preference of Amazonian howlers for flooded forest ecosystems (Queiroz, 1995; Peres, 1997) and the original topography of the area, which was characterized by a complex of fluvial islands.
The negative value recorded for RB85 vs. RB02 is consistent with the fact that the latter represents the same location on the right bank of the Tocantins at a different point in time. The Rst value recorded for this comparison emphatically reinforces that this population has not suffered significant changes in its genetic structure. This may have been reinforced by the fact that, since howlers may survive to up to 20 years in the wild (Wang and Milton, 2003), at least part of the 2002 population may have been present at the site before the flooding. However, few data are available on the longevity of howlers in the wild (and none on A. belzebul), although studies at other sites have indicated a maximum life span of much less than 10 years (Di Fiore and Campbell, 2007), which would preclude this possibility.

The more pronounced differences between Cornélio Island and all other populations (confirmed by the Rst values and AMOVA results) may reflect the relative isolation of this island population. It is possible that formation of the island led to the isolation of a relatively differentiated local subset of the right bank population, which was not sampled in 1985, and has been reinforced by its subsequent isolation.

\section{Implications for conservation of the species}

Overall, the populations of $A$. belzebul show relatively ample genetic variability, with little evidence of significant bottleneck events or loss of variability in comparison with the original, pre-flooding populations. The changes observed were limited to shifts in allelic composition, presumably because of the admixture of local subpopulations during flooding. The phenotypic effects of inbreeding are not apparent at the moment, although the relatively small populations on islands are likely to be susceptible to inbreeding and genetic drift over the long term (Frankham, 1998).

The relatively large number of private alleles recorded in all populations (Table 2) may be a consequence of the Wahlund effect resulting from population admixture, a conclusion supported by the linkage disequilibrium observed in some pairs of loci (not shown). Alternatively, this excess of private alleles may reflect a process of expansion rather than the loss of rare alleles through genetic drift, particularly since rapid population growth enhances the retention of new mutations (Avise et al., 1984; Rogers and Harpending, 1992). Since genetic variability is essential for the adaptation of a species to novel environments (Frankham, 2003), this parameter is an important indicator of the relatively good genetic viability of the populations, at least in the short term.

Various studies (e.g. Chiarello, 2003; Ferrari et al., 2003; Gilbert, 2003; Rodriguez-Toledo et al., 2003; Camargo CC, MSc Dissertation, Museu Paraense Emílo Goeldi, Belém, PA, 2005) have shown that howlers are not only highly tolerant of habitat disturbance, but may actually 
thrive in fragmented landscapes. Despite their ecological flexibility, which is based on folivory, howlers are not exempt from the long-term effects of the loss of genetic diversity or the accumulation of deleterious alleles. Tucuruí is unusual because of the effective isolation of fragments (= islands) by water, rather than a terrestrial matrix, across which howlers may disperse more easily. Given this, the regular monitoring of the genetic variability of these populations, especially those on islands, should be an integral component of long-term management strategies.

\section{Acknowledgments}

This study was supported by FINEP, Eletronorte S.A. and CNPq research fellowships to ECG (152757/2007-4), SFF (302747/2008-7), AS and MPCS. Live captures in 2002 were authorized by IBAMA through special license 080/02-DIFAS/DIREC/IBAMA. We thank Paulo Castro, Eldianne Lima, Simone Martins and local field assistants for collecting specimens, and Rubens Ghilardi Jr., Tacachi Hatanaka and Edilene Nunes for their help with planning and logistics. We also thank an anonymous reviewer for helpful comments on an earlier version of the manuscript.

\section{References}

Avise JC, Neigel JE and Arnold J (1984) Demographic influences on mitochondrial DNA lineage survivorship in animal populations. J Mol Evol 20:99-105.

Bjilsma R, Bundgaard J and Boerema AC (2000) Does inbreeding affect the extinction risk of small populations? Predictions from Drosophila. J Evol Biol 13:502-514.

Bonvicino CR (1989) Ecologia e comportamento de Alouatta belzebul (Primates, Cebidae) na Mata Atlântica. Rev Nordest Biol 6:149-179.

Camargo CC and Ferrari SF (2007) Interactions between tayras (Eira barbara) and red-handed howlers (Alouatta belzebul) in eastern Amazonia. Primates 48:147-150.

Chiarello AG (2003) Primates of the Brazilian Atlantic Forest: The influence of forest fragmentation on survival. In: Marsh LK (ed) Primates in Fragments. Kluwer Academic Press, New York, pp 99-121.

Cornuet JM and Luikart G (1996) Description and power analysis of two tests for detecting recent population bottlenecks from allele frequency data. Genetics 144:2001-2014.

Couvet D (2002) Deleterious effects of restricted gene flow in fragmented populations. Conserv Biol 16:369-376.

Di Fiore A and Campbell CJ (2007) The atelines: Variation in ecology, behavior, and social organization. In: Campbell CJ, Fuentes A, MacKinnon KC, Panger M and Bearder SK (eds) Primates in Perspective. Oxford University Press, New York, pp 155-185.

Di Rienzo A, Peterson AC, Garza JC, Valdes AM, Slatkin M and Freimer NB (1994) Mutational processes of simplesequence repeat loci in human populations. Proc Natl Acad Sci USA 91:3166-3170.

Ellsworth JA and Hoelzer GA (1998) Characterization of microsatellite loci in a New World primate, the mantled howler monkey (Alouatta palliata). Mol Ecol 7:657-658.
Escobar-Páramo P (2000) Microsatellite primers for the wild brown capuchin monkey Cebus apella. Mol Ecol 9:107-108.

Excoffier L, Smouse PE and Quattro JM (1992) Analysis of molecular variance inferred from metric distances among DNA haplotypes: Application to human mitochondrial DNA restriction data. Genetics 131:479-491.

Ferrari SF, Iwanaga S, Ravetta AL, Freitas FC, Sousa BAR, Souza LL, Costa CG and CoutinhoPEG (2003) Dynamics of primate communities along the Santarém-Cuiabá highway in south-central Brazilian Amazonia. In: Marsh LK (ed) Primates in Fragments. Kluwer Academic Press, New York, pp 123-144.

Frankham R (1998) Inbreeding and extinction: Island populations. Conserv Biol 12:665-675.

Frankham R (2003) Genetics and conservation biology. C R Biol 326:22-29.

Frankham R, Ballou JD and Briscoe DA (2002) Introduction to Conservation Genetics. Cambridge University Press, Cambridge, $642 \mathrm{pp}$.

Gilbert AK (2003) Primates and fragmentation of the Amazon forest. In: Marsh LK (ed) Primates in Fragments. Kluwer Academic Press, New York, pp 145-157.

Gonçalves EC, Silva A, Barbosa MSR and Schneider MPC (2004) Isolation and characterization of microsatellite loci in Amazonian red-handed howlers Alouatta belzebul (Primates, Plathyrrini). Mol Ecol Notes 4:406-408.

Gonçalves EC, Ferrari SF, Coutinho P, Menezes EV, Silva A and Schneider MPC (2009) Limited dispersal and genetic structure of silvery marmosets (Mico argentatus) in the fragmented landscape of central Amazonia. In: Davis LC, Ford SM and Porter LM (eds) The Smallest Anthropoids: The Marmoset/Callimico Radiation. Springer Verlag, New York, pp 205-220.

Goudet J (1995) FSTAT v. 1.2: A computer program to calculate F-statistics. J Hered 86:485-486.

Grativol AD, Ballou JD and Fleischer RC (2001) Microsatellite variation within and among recently fragmented populations of the golden lion tamarin (Leontopithecus rosalia). Conserv Genet 2:1-9.

Gregorin R (2006) Taxonomia e variação geográfica das espécies do gênero Alouatta Lacépède (Primates, Atelidae) no Brasil. Rev Bras Zool 23:64-144.

Keller LF and Waller DM (2002) Inbreeding effects in wild populations. Trends Ecol Evol 17:230-241.

Kimura M and Crow JF (1964) The number of alleles that can be maintained in a finite population. Genetics 49:725-738.

Kimura M and Ohta T (1978) Stepwise mutation model and distribution of allelic frequencies in a finite population. Proc Natl Acad Sci USA 75:2868-2872.

Leberg PL (2002) Estimating allelic diversity: Effects of sample size and bottlenecks. Mol Ecol 11:2445-2449.

Lopes MA and Ferrari SF (2000) Effects of human colonization on the abundance and diversity of mammals in eastern Brazilian Amazonia. Conserv Biol 14:1658-1665.

Luikart G and Cornuet JM (1998) Empirical evaluation of a test for identifying recently bottlenecked populations from allele frequency data. Conserv Biol 12:228-237.

Mascarenhas BM and Puorto G (1988) Nonvolant mammals rescued at the Tucuruí dam in the Brazilian Amazon. Primate Conserv 9:91-93. 
Menescal LA, Gonçalves EC, Silva A, Ferrari SF and Schneider MPC (2009) Genetic diversity of red-bellied titis (Callicebus moloch) from eastern Amazonia based on microsatellite markers. Biochem Genet 47:235-240.

Milton K, Lozier JD and Lacey EA (2009) Genetic structure of an isolated population of mantled howler monkeys (Alouatta palliata) on Barro Colorado Island, Panama. Conserv Genet 10:347-358.

Nievergelt CM, Mundy NI and Woodruff DS (1998) Microsatellite primers for genotyping common marmosets (Callithrix jacchus) and other callitrichids. Mol Ecol 7:14321434.

Peres CA (1997) Effects of habitat quality and hunting pressure on arboreal folivore densities in Neotropical forests: Acase study of howler monkeys (Alouatta spp.). Folia Primat 68:199-222.

Petit RJ, El Mousadik A and Pons O (1998) Identifying populations for conservation on the basis of genetic markers. Conserv Biol 12:844-855.

Pinto ACB, Ramos CA and Carvalho Jr O (2003) Activity patterns and diet of the howler monkey Alouatta belzebul in areas of logged and unlogged forest in eastern Amazonia. Anim Biodiv Conserv 26:39-49.

Piry S, Luikart G and Cornuet JM (1999) BOTTLENECK: A computer program for detecting reductions in the effective size using allele frequency. J Hered 90:502-503.

Queiroz HL (1995) Preguiças e Guaribas: Os Mamíferos Folívoros Arborícolas do Mamirauá. Sociedade Civil Mamirauá and CNPq, Brasília, 120 pp.

Raymond M and Rousset F (1995) GENEPOP v. 1.2: Population genetics software for exact tests and ecumenicism. J Hered 86:248-249.

Reed DH and Frankham R (2003) Correlation between fitness and genetic diversity. Conserv Biol 17:230-237.

Rice WR (1989) Analyzing tables of statistical tests. Evolution 43:223-225.

Rodriguez-Toledo EM, Mandujano S and Garcia-Orduña F (2003) Relationships between forest fragments and howler monkeys (Alouatta palliata mexicana) in southern Vera
Cruz, Mexico. In: Marsh LK (ed) Primates in Fragments. Kluwer Academic Press, New York, pp 79-97.

Rogers AR and Harpending H (1992) Population growth makes waves in the distribution of pairwise genetic differences. Mol Biol Evol 9:552-569.

Sambrook J, Fritsch EF and Maniatis T (1989) Molecular Cloning: A Laboratory Manual. Cold Spring Harbor Press, Cold Spring Harbor.

Schlötterer C, Kauer M and Dieringer D (2004) Allele excess at neutrally evolving microsatellites and the implications for tests of neutrality. Proc Biol Sci 271:869-874.

Schneider H, Sampaio MIC, Schneider MPC, Ayres JM, Barroso CML, Hamel AR, Silva BTF and Salzano FM (1991) Coat color and biochemical variation in Amazonian wild populations of Alouatta belzebul. Am J Phys Anthropol 85:85-93.

Schneider S, Roessli E and Excoffier L (2000) Arlequin v. 3.11: A software for population genetic data analysis. Genetics and Biometry Laboratory, University of Geneva, Geneva.

Wang E and Milton K (2003) Intragroup social relationships of male Alouatta palliate on Barro Colorado Island, Republic of Panama. Int J Primatol 24:1227-1243.

Wright S (1931) Evolution in mendelian population. Genetics 16:97-159.

Yeh FC, Yang RC and Boylet T (1997) POPGENE v. 1.32: Software Microsoft Windows based freeware for population genetic analysis. University of Alberta, Canada.

\section{Internet Resources}

Arlequin: http://gb.unige.ch/arlequin/ (August 2, 2009).

Bottleneck: http://www.ensam.inra.fr/URLB/bottleneck/bottleneck.html (August 2, 2009).

Fstat: http://www2.unil.ch/popgen/softwares/fstat.htm (August 2, 2009).

Genepop on the web: http://genepop.curtin.edu.au/ (August 2, 2009).

Popgene: http://www.ualberta.ca/_fyeh/(August 2, 2009).

Associate Editor: João S. Morgante

License information: This is an open-access article distributed under the terms of the Creative Commons Attribution License, which permits unrestricted use, distribution, and reproduction in any medium, provided the original work is properly cited. 